\title{
VALIDATION OF A SURGE MODEL BY FULL SCALE TESTING
}

\author{
J.P.M. Smeulers, M.Sc \\ Senior Scientist \\ TNO Science \& Industry \\ Delft, The Netherlands \\ D.Meulendijks, M.Sc. \\ $R \& D$ Engineer \\ TNO Science \& Industry \\ Delft, The Netherlands
}

\author{
H.J. Slot, M.Sc. \\ R\&D Engineer \\ TNO Science \& Industry \\ Delft, The Netherlands
}

\begin{abstract}
Surge of turbo compressors can cause large stepwise changes in flow and pressure, which can potentially damage the compressor and any equipment that is in direct connection with the compressor. Surge is usually avoided by an anti surge controller (ASC). However, in spite of the ASC surge cycles may occur. A more robust approach is therefore to design the compressor, piping lay-out and attached equipment such that surge cycles can be sustained.

For the evaluation of the effect of surge on a new centrifugal compressor it was intended to apply a model that simulates the flow and pressure variations that occur during a deep surge cycle. In order to increase the confidence in the reliability of the model, experimental data from two existing compressor systems forced into surge were compared with the results of simulations.

It appeared that the simulation results compared very well with the measurements. As a next step, the model has been applied to evaluate the forces that can occur on a cooling circuit in the driver.
\end{abstract}

\section{INTRODUCTION}

The gas and oil industry relies to a great extent on rotating equipment. Therefore the reliability and availability is of eminent importance. It is therefore equally important to evaluate and control extreme static and dynamic loads on equipment and pipe system. An important dynamic load that can occur in turbo compressors is surge. In spite of an Anti Surge Control (ASC), it appears that in practice surge cycles can not be avoided in all cases. For instance in many cases during power fail the ASC (Anti Surge Control) is not fast enough to avoid compressor surge. For this reason it is better to know what the dynamic loads are resulting from a surge cycle and to account for it in the design.

During surge reversal of the flow through the compressor will cause large variations of the suction and discharge pressure. This induces extreme dynamic loads on the compressor internals but also on the attached equipment and piping. Therefore it is important that as part of the design of a compressor system the dynamic loads caused by surge are evaluated.

This paper is organized as follows. First, we present the model with which a surge cycle can be simulated accurately. The model includes both the compressor and the response of the pipe system. Then the validation of the model is presented by means of test results of two compressors in a test rig of GE Oil \& Gas in Massa, Italy. Finally the possible applications of the model are shortly discussed.

\section{MODELLING COMPRESSOR SURGE}

As axial compressors are more sensitive to surge than radial compressors most of the literature is about surge in axial machines. The first model that describes surge in a turbo compressor in a general way as a lumped parameter system has been developed by Greitzer (1976). The model is schematically depicted in Figure 1. It describes the compressor system by means of a limited number of parameters. The compressor itself is described by means of a head-flow curve combined with a certain inertia. The compressor is coupled to a discharge plenum and a throttle, which represent the volume of the discharge system and a load curve, respectively. For the purpose of modeling the flow through the compressor beyond the surge point, the head-flow curve is extended into the unstable part left of the surge point as a third order polynomial with a minimum at zero flow.

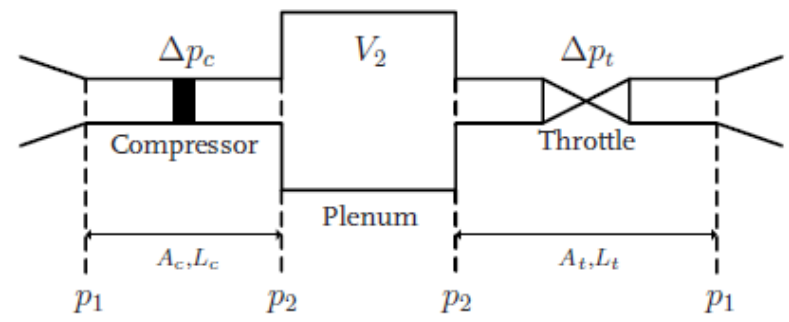

Figure 1 Schematic of the Greitzer model.

Helvoirt (2007) has analyzed the model in detail for the purpose of surge control and described the way in which the model parameters can be calculated. In the current model an 
approach is followed in which the compressor part is equal to the Greitzer model and the models of the suction and discharge system are replaced by a more sophisticated model that describes the response of the pipe system in more detail.

\section{The compressor model}

The model of the compressor is lumped into two elements: the compression part that is described by a head-flow curve and an inertia element that describes the inertia of the fluid in the compressor.

In the approach of Moore and Greitzer (1986) the headflow curve is a third order polynomial with a minimum for zero flow. The curve is further defined by the top of the characteristic as is shown in Figure 2. The right hand branch of the curve is the stable part of the characteristic and the top is the surge point $\left(m_{c}, \Delta p_{c}\right)$. Left of the surge point is the unstable part of the characteristic, i.e. a positive slope. For negative flows the slope of the characteristic is again negative. The characteristic depends also on the compressor speed $N$.

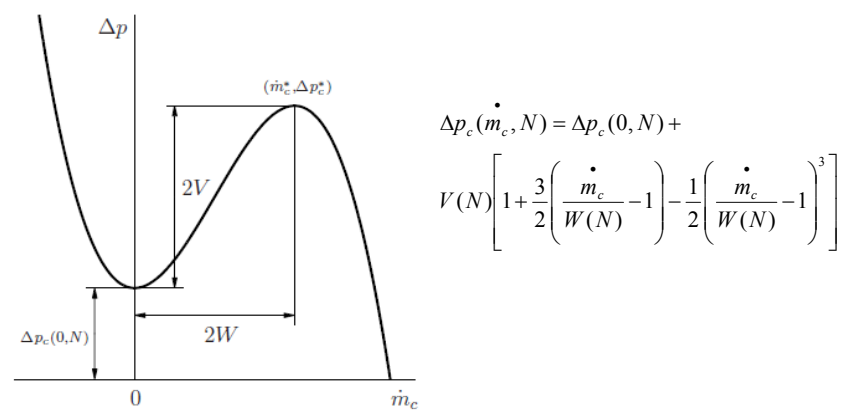

Figure 2 Approximation of the head-flow characteristic of a turbo compressor according to Moore and Greitzer (1986).

In the current model the stable region is based on a polynomial fit on either actual test data or on curves specified by the manufacturer. The unstable region is modeled according to the method of Moore and Greitzer (Figure 2). In the model the effects of compressor speed and Inlet Guide Vane (IGV) position are included by fitting curves for various speeds and IGV settings.

The head at zero flow $\left(\Delta p_{c}(0, N)\right)$ is usually not specified by the compressor manufacturer. It appears from the tests by Helvoirt (2007) that this parameter can be calculated from the inlet conditions, compressor speed and stage dimensions (impeller inlet, outlet diameters and impeller tip speed) A derivation and the exact formula for $\Delta \mathrm{pc}(0, \mathrm{~N})$ is given by Gravdahl and Egeland (1997), which is also implemented in the current model.

As originally the model was applied to axial compressors the fluid inertia could be modeled as a duct with a mean flow area $\left(A_{C}\right)$ and a length equal to the flow path $\left(L_{C}\right)$ through the machine. The inertia effect can then be quantified by the Equation [1]:

$$
\frac{L_{C}}{A_{C}} \frac{d \dot{m}_{c}}{d t}=\Delta p_{c}\left(\dot{m}_{c}, N\right)-\Delta p
$$

For a radial compressor the flow path is complex so that no well defined length and area can be identified. The applied method is to calculate the parameter $L_{C} / A_{C}$ by means of an integral along the gas path (see Equation [2]).

$\frac{L_{C}}{A_{C}}=\int_{\text {suction }}^{\text {discharge }} \frac{d x}{A_{C}}$

One of the objectives of the current validation is to determine the sensitivity of the surge behavior to this parameter.

\section{The pipe system model}

In the Greitzer model (see Figure 1) the pipe system is replaced by a lumped volume, representing the distributed volume of the discharge pipe system, and a throttle that simulates the back pressure. The suction pipe system is not modeled at all and is replaced by a constant pressure boundary. These simplifications make the model accessible for an analytical solution, which greatly increases the insight into the surge phenomenon. As demonstrated by Helvoirt (2007) for a relatively simple pipe system these simplifications are too crude for a more detailed surge cycle analysis. Therefore surge analysis of compressors in process installations with a piping network at both suction and discharge side of the compressor requires a model of the suction and discharge piping that accounts for the pressure wave propagation. This model should simulate the pressure variations in all components of the piping that affect the pressures at the suction and discharge of the compressor. Such a model includes pipe sections, volumes (for instance scrubbers and separators), heat exchangers, control and check valves, etc.

Such a piping network model can be built easily with the PULSDS program, which contains a set of simulation elements required to build a model of any piping network. PULSDS is one of the programs in PULSIM Suite, developed for the simulation of several kinds of dynamic phenomena in installations, i.e. pipe systems and rotating and static equipment. A graphical user interface supports building of the model of an installation. In PULSIM Suite the model is represented as a three dimensional geometry showing all elements of the system. An example, the representation of the model of the test rig, is shown in Figure 4.

In the PULSDS program pipe sections are divided into elements. For each pipe element the one-dimensional continuity, impulse and energy equations are solved on basis of time stepping. The solver includes an equation of state for real gas, heat exchange with the pipe wall and environment. If required also variations of the gas composition called "compositional tracking" are modeled. These features allow a true modeling of both the stationary and dynamic behavior of a compressor system. In addition to pipe elements also simulation elements are included that solve the aforementioned equations for pipe bends, pipe branches, volumes, valves (including the Joule Thomson effect) and a turbo compressor stage.

The turbo compressor model is defined by specifying the performance curves, i.e. head-flow, efficiency-flow and powerflow curves, stage by stage or by one set for a cascade of stages. The compressor model is coupled with the models of the 
suction and discharge pipe systems and calculates the flow through the stage and the discharge temperature using the suction and discharge pressures, the suction temperature and density. The compressor model can be controlled both by the rotation speed and/or the position of inlet guide vanes (IGVs). A compressor stage model can be connected to a rotor and a driver model with which inertia and input power variations can be modeled.

An important feature of PULSDS is that also control elements can be included in a model. A versatile PID controller can accept various parameters in the model, such as pressure, flow and temperature, as an input to control valves or a compressor through the speed (directly or via a driver) or IGV position.

Also various anti surge controllers (ASC) are available, which depending on the control algorithm require multiple inputs.

\section{THE TESTRIGS}

Performance tests have been made on a configuration with two multi-stage compressors in two casings with a common driver. In fact the configuration can be seen as two separate compressors, one low pressure (LP) and one high pressure (HP) compressor. In addition to the regular performance tests also tests of the surge behavior have been made both on the LP and HP compressor.

\section{General compressor data}

The compressors have been tested using two separate closed loops. The main data are shown in Table 1.

Table 1 Summary of compressor data for the nominal operating conditions.

\begin{tabular}{|l|c|c|}
\hline Parameter & $\begin{array}{c}\text { LP } \\
\text { compressor }\end{array}$ & $\begin{array}{c}\text { HP } \\
\text { compressor }\end{array}$ \\
\hline Speed [RPM] & 10925 & 10925 \\
\hline Flow rate $\left[\mathrm{m}^{3} / \mathrm{h}\right]$ & 4027 & 1289 \\
\hline Suction pressure $[$ bara] & 14.335 & 128.86 \\
\hline Suction temperature $\left[{ }^{\circ} \mathrm{C}\right]$ & 35.0 & 49.5 \\
\hline Discharge pressure $[$ bara] & 39.5 & 304.32 \\
\hline Discharge temperature $\left[{ }^{\circ} \mathrm{C}\right]$ & 133.0 & 136.5 \\
\hline Number of stages $(\#$ wheels) & 5 & 6 \\
\hline Polytropic efficiency & 0.80 & 0.73 \\
\hline Power $[\mathrm{MW}]$ & 7.5 & 10 \\
\hline
\end{tabular}

The compressors have been tested in a closed circuit operated with natural gas ( 85 percent methane, molecular weight $18.87 \mathrm{~kg} / \mathrm{kmol}$ ). The gas composition was close to the composition in the final installation. During the surge tests the compressors have been operated at constant speed.

The performance curves have been obtained from the tests at stationary conditions. Though the tests included conditions near the surge point, the surge point indicated in Figure 3 is a result of an extrapolation.

As discussed in the previous section the curve left of the surge point is derived from head and flow at the surge point and the head at zero flow. In addition it has been assumed that the curve runs horizontal at both points. This is still a difficult point in the modelling, as in most of the cases the surge point that is found by testing appears not to be the maximum of the flowhead curve. In that case we take the maximum of the fitted head flow curve as the surge point instead of the tested point.

The $L_{C} / A_{C}$ parameter has been calculated from the geometry of the compressor internals. The values found in this way are $111.1\left[\mathrm{~m}^{-1}\right]$ for the LP and $225.4\left[\mathrm{~m}^{-1}\right]$ for the HP compressor.

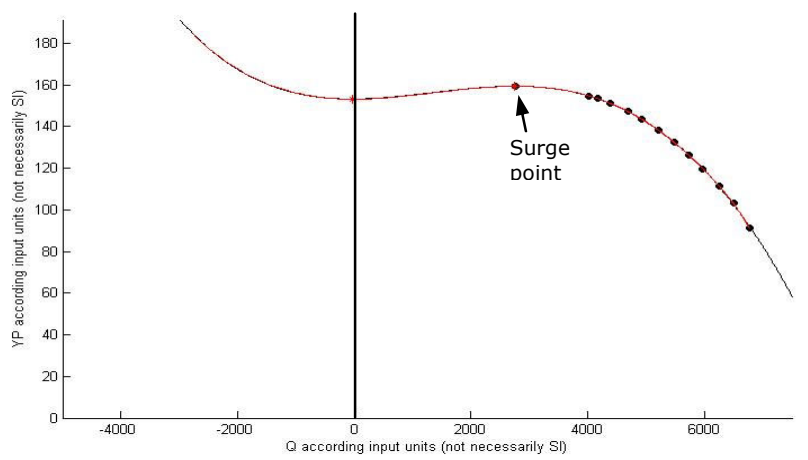

Figure 3 Head-flow curve of the HP compressor extended to the unstable operating range.

\section{Lay-out of the test loop}

Two similar test loops have been built: one for the LP and one for the HP compressor test. The system is a closed loop (see Figure 4) in which the discharge system is a single pipe section that at the end branches out to three pressure control valves $(\mathrm{PCV})$ of different sizes with which the flow through the compressor can be controlled. Downstream of the PCVs the flow is fed into a cooler that consists of four banks of parallel pipes. In the model each bank is represented by one hairpin shaped pipe with the same length, an equivalent flow area and the same flow friction coefficient so that the pressure loss in the cooler is equal to the real pressure loss. After the cooler the gas flows through an in-line filter to the suction nozzle of the compressor.

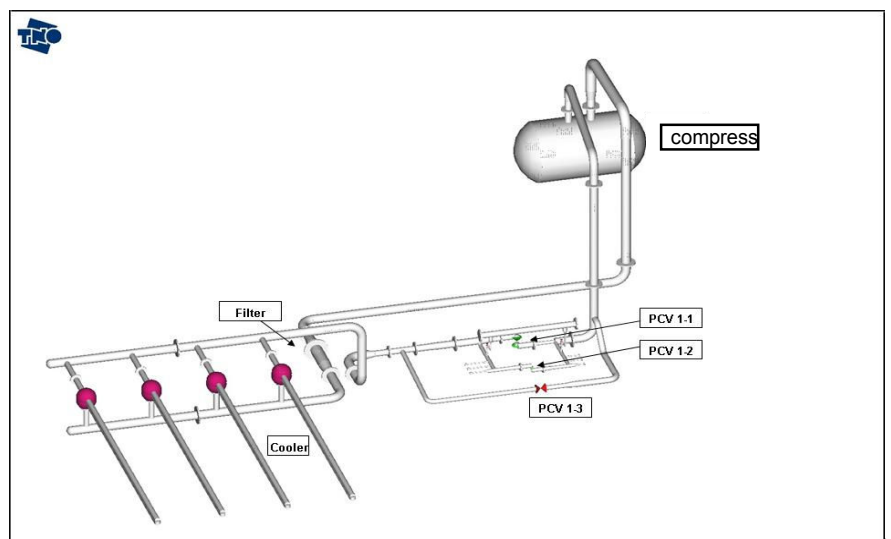

Figure 4 Lay-out of the test loop of the LP compressor. The loop for the HP compressor is very similar.

The test loop for the LP compressor has the following dimensions. The length of the suction pipe between filter and suction nozzle is ca. $25 \mathrm{~m}$ with a diameter of $12 \mathrm{inch}$. The 
discharge line is shorter, i.e. the length between discharge nozzle and branch to the PCVs is ca. $13 \mathrm{~m}$. The diameter of the discharge line is $10 \mathrm{inch}$. For the HP compressor test loop the suction and discharge line diameters are $10 \mathrm{inch}$, and the lengths of the system are similar to the LP loop.

\section{COMPARISON OF SIMULATIONS AND MEASUREMENTS}

The surge tests have been carried out by starting at the nominal operating point as specified in Table 1 and slowly closing one of the PCVs, in order to reduce the flow and at the same time to increase the discharge pressure, until eventually the compressor starts to surge. After a few surge cycles the $\mathrm{PCV}$ is opened so that the compressor returns to a stable operating condition. During the test the compressor speed is kept constant and the pressure variations are measured at the suction and discharge nozzles.

The same tests have been simulated in the model. Besides the pressures at the suction and discharge nozzles, which can be compared with the measurements, also other parameters have been recorded, such as the flow through the compressor.

In Figure 5 the measured and simulated pressures at the suction and discharge nozzles of the LP compressor are compared in the time domain and in Figure 6 in the frequency domain. It appears that the amplitudes compare very well and that there are differences for the higher frequencies. The differences can be explained from the fact that the pressure measurement system has a limited frequency response that quickly decays at higher frequencies.
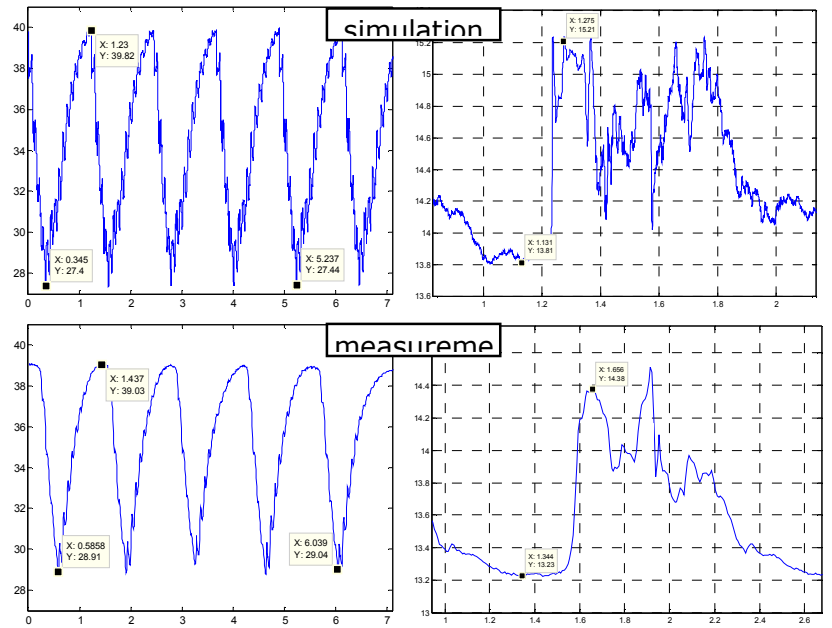

Figure 5 Comparison of the simulated (upper graphs) and measured (lower graphs) pressure variations at the discharge (left) and suction (right) nozzle of the low pressure compressor.

The pressure variations at the discharge side (ca. 10 bar peak to peak or 9 percent of the mean pressure) are approximately a factor of 20 larger than at the suction side (ca. 0.5 bar peak to peak or 3.5 percent of the mean pressure). The surge cycle frequency is $0.77 \mathrm{~Hz}$ and shows also harmonics of this frequency. In the discharge the higher harmonics are relatively weak. In the suction higher harmonics are larger because the response of the suction system is more complex than the response of the discharge system, which only consists of one relatively short pipe section without branches.
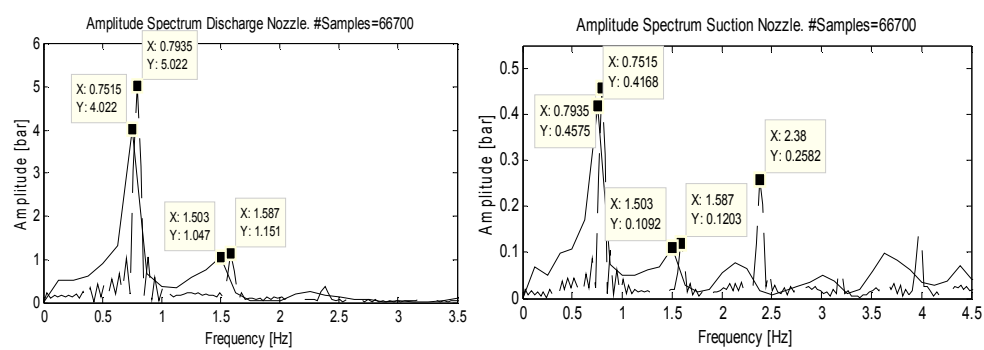

Figure 6 Comparison of the spectra of the measured (solid line) and simulated (dashed line) pressure variations at the discharge (left) and suction (right) nozzles of the low pressure compressor.

In addition to the measured pressures at the suction and discharge nozzle at all points in the pipe system and compressor the pressures, flow velocities, temperatures and gas densities can be obtained from the simulation model. In this paper we only present the flow through the compressor. See Figure 7.

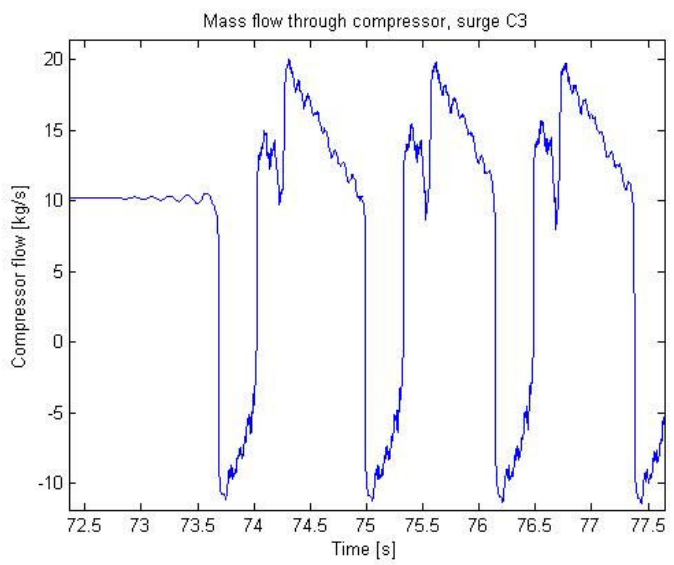

Figure 7 Simulated flow through the compressor during surge.

It appears that the surge cycles become repetitive in a short number of cycles. "Deep surge", i.e. flow reversal, occurs resulting in steep gradient at the time the work point jumps from the stable branch of the flow-head curve to the branch at negative flow and another jump in the opposite direction.

Comparable results have been obtained for the HP compressor. However, because of the higher mean pressure the pressure variations are larger, i.e. 90 bar peak to peak at the discharge and 14 bar peak to peak at the suction nozzle (respectively 30 percent and 11 percent of the mean pressure). Though the surge cycle frequency is low still very fast pressure changes occur each time at the start of a surge cycle. The steepness of the pressure steps depends on the $L_{C} / A_{C}$ parameter. 
This means that during a surge cycle large pressure gradients occur in the pipe system and inside the compressor and as a consequence large dynamic forces.

In a sensitivity analysis a number of parameters have been varied. Variation of the velocity of sound changes the surge cycle frequency, but in this case the velocity of sound does hardly affect the amplitude. Variation of the shape of the flowhead curve, i.e. surge point and head at zero flow, affects both amplitude and frequency of the surge cycle. However, in this case it did not improve the comparison with the test results. The position of the throttle valve affects the response of the discharge system and thus mainly the frequency of the surge cycle and to a lesser extent the amplitude.

Variation of the $L_{C} / A_{C}$ parameter shows that the comparison can be slightly improved by increasing this parameter by 10 percent. This reduces the surge cycle amplitude slightly, but the main effect is a reduction of the steepness of the pressure gradient at the start of a surge cycle. However, the sensitivity of this parameter on the simulation results is very limited, which demonstrates the robustness of the model.

\section{APPLICATIONS}

In this case the primary application of the validated surge model has been the calculation of the pulsation forces on a cooling circuit of an electric motor. This electric motor is part of a seal-less compressor that is being developed at GE Oil and Gas in Florence (see references). In this new design a compressor is applied that is similar to the LP compressor that has been tested and simulated. The compressor is integrated in one casing with an electric motor that is cooled by a part of the gas stream through the compressor. This is achieved by branching off a part of the suction flow, circulate it through the cooling circuit by means of a fan and releasing the heated gas in the suction line at a point closer to the compressor.

For this case the compressor and pipe system at suction and discharge have been modeled to simulate the surge cycles. This model has been extended with a model of the cooling circuit, which consists of a complex network of channels, volumes and flow resistances that has been modeled as an equivalent piping network. With this model the pulsations and, more important, the pulsation induced forces occurring during a surge cycle on various parts of the cooling circuit have been calculated. Using the pulsation forces the integrity of the cooling circuit could be assessed.

As well as the integrity of a cooling circuit can be a problem, which was the subject of this paper, also the connected pipe system and the compressor internals can be damaged during a surge cycle. In order to protect the compressor an Anti Surge Control (ASC) is considered as a necessity in turbo compressor installations. However, it is our experience that in many installations the ASC is adequate for normal changes in the process, but is not fast enough to avoid surge in critical situations like in case of an emergency shutdown or power failure. Improving the ASC response is in many cases not feasible as this requires a very fast response of the slowest component in the control loop, i.e. the anti surge control valve. Valves of the required size with a response time of less than one second are simply not available as a standard component. Therefore it is important to be able to analyze the surge cycles that can occur in these extreme situations and to evaluate the effect on the pipe system and compressor internals.

\section{Surge (cycle) analysis}

With the model presented in this paper the possibility of surge cycles can be analyzed that can occur in a compressor installation at abnormal conditions. The model has been applied to compressor installations used for gas production, gas booster stations, and compressors applied in the process industries. The objective of such an analysis is to design the compressor plus pipe system and the ASC (Anti Surge Control) such that surge is avoided for all operating conditions including exceptional conditions like power fail. During power fail the compressor will loose speed quickly. As without rapid opening of the ASV (Anti Surge Valve) the discharge pressure will stay approximately the same and the work point will rapidly move to the surge line. To avoid this, the ASV has to be opened sufficiently fast to release the discharge pressure. This requires a minimum response time of the ASV and a capacity that matches with the volume of the discharge system, i.e. the volume of the pipe system between the discharge of the compressor and the non return valve (NRV) in the discharge line. It should be noticed that the response time of the NRV (non return valve) should be at least as fast as the ASV.

In a surge analysis the various alternative ASC configurations are analyzed. An example of such an analysis is shown in Figure 8.
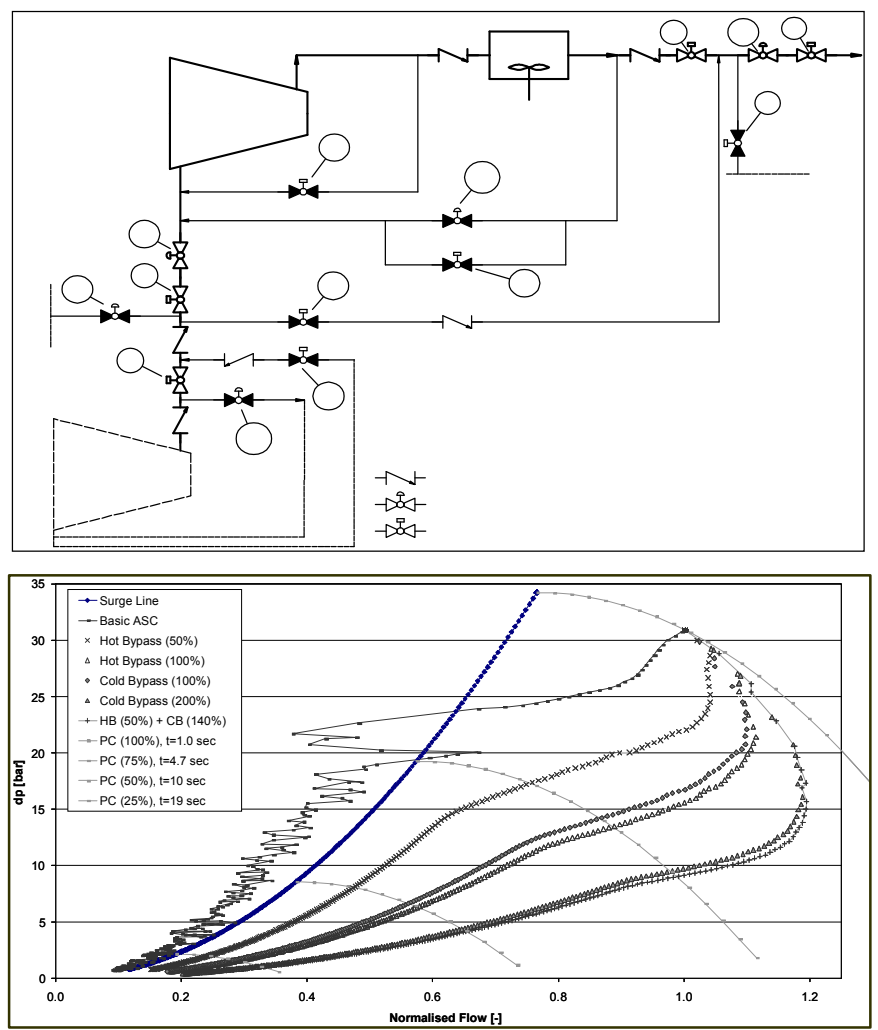

Figure 8 Example of a comparison of various ASC configurations for a compressor system. The upper graph shows the process schematic. The lower graph the calculated responses to a power fail. 
It often appears that it is not possible to avoid surge or that an ASC with extreme requirements is needed. An example is a case where a four stage air compressor was analyzed that showed failures caused by surge cycles during a small number of power fails. In order to avoid surge during power fail an ASV was required with an opening time of 0.2 seconds, which simply did not exist. In such cases it is worthwhile to investigate if the requirements of the ASC can be mitigated by allowing a limited number of (weak) surge cycles at reduced speed. In order to decide on this the model presented in this paper is used to determine the number and magnitude of the surge cycles that can occur during exceptional operating cases. For this analysis it should be known what surge cycles the compressor internals can sustain. This is still information that can not be specified by the compressor manufacturer. At most the maximum number of surge cycles that is allowed will be specified, which is based on practical experience and not on analysis. Therefore the effect of surge cycles on the compressor internals is an interesting topic for research and development.

\section{System Dynamics Simulation}

Today it is considered more and more a good engineering practice to perform a System Dynamic Simulation (SDS) of a compressor installation to optimize the combination of compressor(s) and pipe systems for integrity and controllability. In these studies the validated surge model presented here is applied for optimization of the operating envelope, by minimizing the surge margin, and efficiency, by avoiding as much as possible the necessity to open the anti surge by-pass. Also the optimal ASC configuration is determined and the minimum requirements for the ASC are specified. Especially the required capacity and speed of the ASV need to be specified in an early stage of the design, as this is an expensive item with usually long delivery times. In addition, in case surge cycles can not be avoided, with the model presented here the pressure and flow variations that occur during surge can be calculated. These data can be used to evaluate the effect on pipe system and compressor internals.

The effect of pressure and flow fluctuations on the pipe system can be analyzed by a mechanical response calculation. From this analysis it may appear to be necessary to improve the pipe supports. A different issue is the effect of surge cycles on the integrity of the compressor. It is known that axial compressors are more vulnerable to surge than radial machines. Nevertheless also failures of radial machines have been reported with surge as a likely root cause. In either cause there is no method to evaluate the effect of a surge cycle on the compressor. Common practice is that the compressor manufacturer specifies the number of surge cycles that the compressor can sustain. Better knowledge of the effects of surge cycles on the compressor can lead to less severe requirements for the ASC and anti surge control valves and improved reliability of the compressor.

\section{CONCLUSIONS}

The validation of the surge model presented here has greatly improved the confidence in the modeling of turbo compressor dynamics. It is remarkable that a relatively simple model of the compressor leads to accurate predictions. This can be attributed to the fact that a surge cycle is determined to a great extent by the interaction between compressor and pipe system. Therefore it is important to put effort in the correct modeling of the connected pipe system.

Though the surge cycle occurs at a low frequency, a cycle starts with a quite steep and large pressure decrease (up to 30 percent of the mean pressure) at the discharge side and a much smaller (up to 10 percent of the mean pressure) but equally steep pressure increase at the suction side. This causes that the pulsation forces on the piping can be large, which may require additional pipe supports. Additionally, large forces on the internals of the compressors will occur during surge. This requires special attention for and analysis of the dynamic loads on impellers vanes and the (magnetic) bearings.

It appears that for high pressure systems the pressure variations caused by a surge cycle are much larger than for low pressure systems, not only in absolute sense but also in percentage of the mean pressure. This means that for high pressure compressors surge cycles are much more violent than for low pressure systems. Therefore a surge analysis is more important for high pressure systems.

The surge model is important for the analysis of the dynamic behavior of compressor systems. By tuning the interaction between compressor and pipe system the requirements for the anti surge control (ASC) can be mitigated or, if surge cycles cannot be avoided, to minimize the magnitude and effect of surge cycles. In this perspective it is worthwhile to perform a system dynamics simulation for compressor installations in the design phase with two objectives: avoid dynamic problems, thus improving the reliability and operating envelope of the installation, and secondly to prevent expensive and time consuming modifications to the system after commissioning.

\section{NOMENCLATURE}

$\mathrm{A}_{\mathrm{C}}=$ Mean flow area in the compressor

$\mathrm{L}_{\mathrm{C}}=$ Length of the flow path through the compressor

$\mathrm{N}=$ Compressor speed

$\mathrm{m}_{\mathrm{C}}=$ Mass flow through compressor

$\mathrm{p}=$ Pressure

$\Delta \mathrm{p}=$ Differential pressure

$\left(\mathrm{FL}^{-2}\right)$

$\mathrm{V}, \mathrm{W}=$ Parameters describing a third order curve

$\mathrm{ASC}=$ Anti Surge Control

$\mathrm{ASV}=$ Anti Surge Valve

$\mathrm{HP}=$ High Pressure

IGV = Inlet Guide Vane

LP = Low Pressure

$\mathrm{PCV}=$ Pressure Control Valve

$\mathrm{PID}=$ Proportional Integrating Differentiating (controller) 


\section{REFERENCES}

J.T. Gravdahl and O. Egeland, 1997, "Control of the Threestate Moore-Greitzer compressor model using a closecoupled valve", In Proceedings of the 1997 European Control Conference.

E.M. Greitzer, 1976, "Surge and Rotating stall in axial flow compressors, Part I Theoretical compression system model", Journal of Engineering for Power, 98:190 - 198.

J.van Helvoirt, 2007, “Centrifugal Compressor Surge Modeling and Identification for Control”, $\mathrm{PhD}$. Thesis, Eindhoven University of Technology

F.K. Moore and E.M. Greitzer, 1986, "A theory of post stall transient in axial compression systems: Part I-

Development of equations", ASME J. Engineering for Gas Turbines and Power, 108, 68-76.

http://www.gepower.com/businesses/ge_oilandgas/en/literature /en/downloads/integrated_compressor_line.pdf

\section{ACKNOWLEDGEMENTS}

The authors wish to thank GE Oil and Gas for their cooperation in this project and the permission to publish this work. 